\title{
FINANCIAL STABILITY ANALYSIS
}

INSIGHTS GAINED FROM

CONSOLIDATED BANKING

\section{DATA FOR THE EU}

By Stefano Borgioli, Ana Cláudia Gouveia and Claudio Labanca 


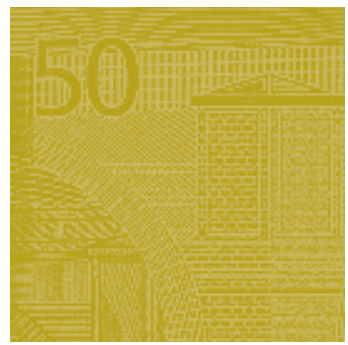

\section{FINANCIAL STABILITY ANALYSIS - INSIGHTS GAINED FROM CONSOLIDATED BANKING DATA FOR THE EU}

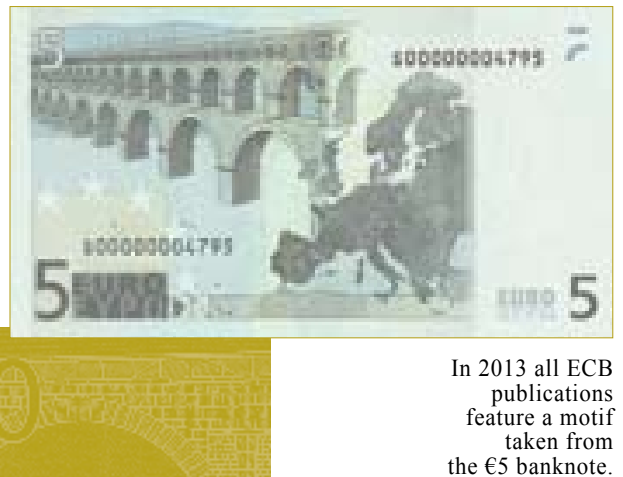

By Stefano Borgioli, Ana Cláudia Gouveia and Claudio Labanca

NOTE: This Occasional Paper should not be reported as representing the views of the European Central Bank (ECB).

The views expressed are those of the authors and do not necessarily reflect those of the ECB.

This paper can be downloaded without charge from http://www.ecb.europa.eu or from the Social Science Research Network electronic library at http://ssrn.com/abstract_id=2184844. 
(C) European Central Bank, 2013

Address

Kaiserstrasse 29

60311 Frankfurt am Main, Germany

\section{Postal address}

Postfach 160319

60066 Frankfurt am Main, Germany

\section{Telephone}

+496913440

Internet

http://www.ecb.europa.eu

Fax

+496913446000

All rights reserved.

Any reproduction, publication and reprint in the form of a different publication, whether printed or produced electronically, in whole or in part, is permitted only with the explicit written authorisation of the ECB or the authors.

Information on all of the papers published in the ECB Occasional Paper Series can be found on the ECB's website, http://www.ecb.europa.eu/ pub/scientific/ops/date/html/index.en.html. Unless otherwise indicated, hard copies can be obtained or subscribed to free of charge, stock permitting, by contactinginfo@ecb.europa.eu

ISSN 1607-1484 (print)

ISSN 1725-6534 (online)

EU catalogue number QB-AQ-13-007-EN-C (print)

EU catalogue number QB-AQ-13-007-EN-N (online) 


\section{CONTENTS}

ABSTRACT

NON-TECHNICAL SUMMARY

I INTRODUCTION

2 THE CONSOLIDATED BANKING DATA

3 COMPARISON OF CBD AND MFI STATISTICS

3.1 Total assets

3.2 Total loans

3.3 Total interbank deposits

4 THE EU BANKING SYSTEM

5 CBD-BASED BENCHMARKING INDICATORS

6 CONCLUSION

ANNEX

REFERENCES 


\section{ABSTRACT}

This occasional paper explores the Consolidated Banking Data (CBD), a key component of the ECB statistical toolbox for financial stability analysis. We show that non-consolidated, host-country Monetary Financial Institutions (MFI) balance sheet data, which constitutes a key source of input into monetary analysis, are a rather weak proxy for consolidated, home-country data and therefore cannot easily substitute CBD for the purposes of macro-prudential assessment. In addition, it is argued that, notwithstanding the relevance of large banks, medium-sized and small banks must also be taken into account in financial stability analysis, given their relevance in several EU countries and their different business models. A discussion follows on how aggregate data, broken down by bank size, can be used to complement micro data, in particular by signalling where and what to look for, again highlighting the differences between large banks on the one hand and small and mediumsized banks on the other.

JEL code: C82, G21

Keywords: Macro-prudential analysis, Consolidated Banking Data, banking indicators. 
As a product of the financial crisis and the need to address stability issues and systemic risk, macro-prudential analysis has moved into the spotlight in recent years. Extensive research on stability and systemic risk issues is being carried out, both at an institutional level and in the academic world. New specialised institutions have been created, such as the European Systemic Risk Board (ESRB). As it is often the case, the feasibility and potential success of macro-prudential initiatives depend on the quality of the available statistics.

This paper explores a key component of the ECB statistical toolbox for financial stability analysis the Consolidated Banking Data (CBD) - and the contribution that this dataset can make to macroprudential banking analysis, both in its own right and in comparison to other sources.

Using the CBD indicators as a starting point, focus is given to three issues connected to financial stability analysis. At the outset, this paper shows how different the results of banking analysis based on consolidated or unconsolidated data can be and how relevant consolidation can be. It goes on to show that, given the configuration of the EU banking industry, limiting the analysis to large banking groups can be non-optimal. Lastly, the paper shows that even though the financial crisis has brought micro databases into the spotlight and high granularity is usually at the top of analysts' list of requirements, the information content of aggregated data should not be overlooked, and again highlights the differences between large banks and small and medium-sized banks. 
Since the onset of the 2007-08 financial crisis, the term macro-prudential has become part of everyday life: economic news, research papers and speeches often include references to it. ${ }^{1}$ As Borio (2010) asks, are we all "macro-prudentialists" now? ${ }^{2}$ The answer seems to be yes.

All over the world, new institutions have been created to address the issue of financial stability, such as the Financial Stability Oversight Council in the United States or the European Systemic Risk Board (ESRB) in the European Union. The success of these initiatives is closely linked to the quality of the statistics available and the tools used to analyse them. In this vein, the ECB is working on the enhancement of its statistics to help the Eurosystem fulfil its responsibilities in the field of financial stability and meet the statistical needs of the ESRB. As ECB Vice-President Vítor Constâncio underlined in 2010, "an important element of the ECB's preparatory work consists of ensuring comprehensive statistical databases for macro-prudential purposes that are available at the level of the EU".

The financial crisis has brought micro databases into the spotlight and high granularity is usually at the top of analysts' lists of requirements. Nevertheless, aggregate data can still play a significant role in leading the way and showing us where and what to look for. As Cecchetti, Fender and McGuire (2010) point out, "the alarms sounded by the aggregate data would yield the critical pieces of information to inform targeted analysis of more detailed data at the firm or market level". The benefits of "top-down" statistical work were also underlined by Governor Marfán of the Central Bank of Chile in his contribution to the fifth ECB Conference on Statistics: "Aggregate ratios such as 'flow change in M3' / national savings or the like can act as a proxy for detecting aggregate imprudent behaviour. I know of no systemic crisis trigger that could not be anticipated by that kind of aggregate measure, which, of course, can and should be disaggregated if necessary" (see ECB, 2011, p. 67).

This paper explores a key component of the ECB statistical toolbox for financial stability analysis: the Consolidated Banking Data (CBD). The CBD dataset, collected since 2002 on an annual basis, five months after the year end, consists of aggregated cross-sectoral and cross-country consolidated data on banks' profitability, balance sheets, assets quality and solvency ratios for the $27 \mathrm{EU}$ countries. Data on the domestic banks of each EU country are reported broken down by bank size (large, medium-sized and small). In addition, data are also separately reported for foreign-controlled branches and subsidiaries active in EU countries. A recent improvement entailed increasing the frequency from annual to twice-yearly (for a subset of indicators), reported with a lag of three months, which was an important step towards making more timely information available. The CBD, which is built from aggregated micro-prudential information, can be used as an important benchmark for the EU banking system, since it covers the entire banking population. ${ }^{3}$ Moreover, it has been recently supplemented on a quarterly basis with fasttracking information for a subset of systemically important banks provided by the European Banking Authority (EBA) to the ESRB.

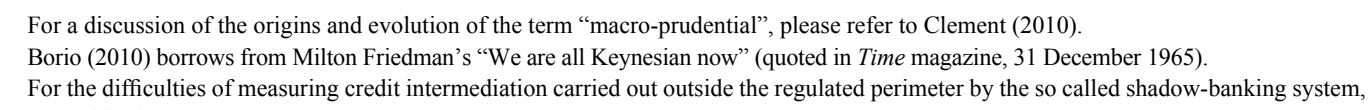


Taking the CBD series and indicators as a starting point, this paper focuses on three assumptions about financial stability analysis:

\section{Non-consolidated, host-country data are a good proxy for consolidated, home-country-approach data}

On the basis of two different datasets, Section 2 of this paper shows how different the results of banking analysis based on consolidated or unconsolidated data can be. The relevance of consolidation, of course, differs from country to country. For rather "closed" national banking systems that are not integrated into the global financial landscape, host-country data could be a good proxy, but this is not the case for most EU countries, which are also strongly interconnected via proprietary and control links.

\section{Aggregate data are of little use to macro-prudential analysts}

Micro data tend to rule these days. As the collection of statistics evolves, firm-level data, securityby-security data and the like are gaining momentum. And they are crucial. Still, the value of (derived) aggregated data should not be overlooked, as such data can potentially provide answers to two critical questions: where should we look and what should we look for? In this paper we explore some techniques for extracting information from the aggregated CBD.

\section{It is enough to monitor large banking groups}

From an EU perspective, large banking groups matter, as they represent around $75 \%$ of the total assets of EU domestic banking groups. Hence, it is crucial to monitor them closely. Still, medium-sized and small banks must also be considered in any financial stability assessment. They represent a sizeable share of the domestic banking system in 18 of the $27 \mathrm{EU}$ countries (ignoring them would imply monitoring only the subsidiaries of large European groups in these countries but not the domestic banks themselves). Moreover, large banks' behaviour is a poor proxy of smaller banks' behaviour, as they have different business models and interact differently with the local economy. Eventually, stress experienced by small and medium-sized intermediaries could also potentially have (close to) systemic relevance if those intermediaries are particularly concentrated into a single asset class, have systemic connections to other intermediaries or are not immediately replaceable.

The paper is organised as follows. Section 2 describes the CBD dataset, Section 3 presents a comparison between the CBD dataset (group consolidated, home-country approach) and the Monetary Financial Institutions balance sheet data (non-group consolidated, host-country approach) available at the ECB, and Section 4 provides a description of the EU banking system, by ownership (domestic and foreign control) and by size of bank, based on the CBD. Section 5 elaborates on possible CBD-based benchmark indicators, bringing into focus the importance of monitoring small and medium-sized banks in addition to the usual monitoring of large banks. Finally Section 6 concludes. 
The CBD constitutes one of the main sources of input of the macro-prudential analysis conducted within the European System of Central Banks (ESCB) and are part of the statistical support of the ECB to the ESRB. These data, which are based on aggregated information on the EU banking system, include detailed information on the profitability, balance sheets, assets quality and solvency ratios of banks in the EU27 countries.

The current CBD collection framework is based on the Financial Reporting (FINREP) guidelines and the Common Reporting (COREP) guidelines, both sponsored by the EBA. ${ }^{4}$ This scheme was implemented for the first time on the occasion of the 2009 data collection, referencing 2008 data, and it has been adopted by all the EU countries for their provisioning of banking data to the ECB. The reporting scheme used to report national data until 2008 was not based on the FINREP/COREP templates. Moreover, data complying with the International Financial Reporting Statistical Standards (IFRS) were treated separately from data complying with local Generally Accepted Accounting Principles (GAAP), since the conceptual differences between the accounting regimes were thought to be too substantial to render the aggregation of IFRS and non-IFRS data meaningful. As a result, until 2008 two sets of separate aggregates were calculated and displayed. ${ }^{5}$ Afterwards, more EU countries moved towards an IFRS reporting framework; this fact, together with the advantage of having a unique reporting scheme, led to the current CBD collection method, which, however, is still partly based on local GAAP.

The data are consolidated on a cross-border basis (data on branches and subsidiaries located outside the domestic market are consolidated in the data reported by the parent institution) and a crosssector basis (branches and subsidiaries of banks that can be classified as "other financial institutions" are included). Insurance companies and non-financial institutions are, in general, not consolidated. The consolidation basis could, therefore, be different from that of the IFRS.

CBD series were reported annually, five months after the end of the reference year. Given the importance of timely and frequent data, a subset of indicators is currently being collected on a twice-yearly basis, with a lag of three months (the first transmission took place in October 2010, referring to June 2010).

The data on EU domestic banks are divided into three groups according to bank size (small, mediumsized and large). "Large" domestic banks for a given reference year are banks with assets totalling more than $0.5 \%$ of the total consolidated assets of EU banks of the previous reference year, while "medium-sized" banks have total assets of between $0.005 \%$ and $0.5 \%$ of the total consolidated assets. Banks with total assets of less than $0.005 \%$ of the total consolidated assets are considered "small". The concept of size is therefore in relation to the EU banking system as a whole and not in relation to each single country.

In addition, information is provided on foreign-controlled institutions active in EU countries. "Foreign banks" are subsidiaries and branches that are controlled by either an EU or a non-EU parent that is "foreign" from the reporting country's point of view.

$4 \mathrm{CBD}$ are basically a subset of the FINREP and COREP templates.

5 See for example ECB (2007). 
In general, when analysing CBD data presented at country level, and especially when attempting a comparison across countries, it should be borne in mind that some country-level indicators differ as regards both coverage and definitions used, apart from differences in the banking sector structure. Indicators of non-performing assets and provisioning, for instance, should be interpreted with caution owing to the current differences between national definitions of

Table I Selected indicators from the CBD dataset

\begin{tabular}{|c|c}
$\begin{array}{c}\text { Profitability and efficiency } \\
\text { - Return on equity (ROE) }\end{array}$ & Capital adequacy \\
& Tier 1 (T1) \\
Asset quality & Liquidity \\
- Non-performing and & - Loans-to-deposits ratio \\
doubtful loans and debt & (LtD) \\
$\begin{array}{l}\text { securities (percentage } \\
\text { of total loans and debt } \\
\text { securities ) (NPL) }\end{array}$ & Leverage \\
\hline
\end{tabular}
impaired assets (non-performing and doubtful

assets) and provisions. Furthermore, the reporting framework differed between IFRS and non-IFRS countries until 2007. A comparison across time should also be performed with caution given that, since 2008, data have been reported in accordance with a new framework. ${ }^{6}$ Lastly, country-level information may differ from that published in individual countries' reports on account of differences in the reporting populations.

This paper presents an analysis of a sub-group of indicators selected from the whole set of indicators that are built and published on the basis of the raw CBD series (see Table 1). ${ }^{7}$ The aim of the selection is to provide a thorough overview of the EU banking sector and to demonstrate the usefulness of CBD series for macro-prudential analysis. The selected indicators are the most commonly used in this type of analysis and they bear, in principle, a close resemblance to the core set of financial soundness indicators of the IMF (see IMF, 2006). ${ }^{8}$

6 Contrary to the previous one, this reporting scheme is the same for IFRS and non-IFRS countries. Special reporting items have been added to cover the non-IFRS supervisory reports of some national banking systems or some sub-components of them.

7 The whole set of indicators is presented in the Statistical Annexes of the EU Banking Sector Stability reports published in the period 20032011 and available on the ECB website at http://www.ecb.europa.eu/stats/money/consolidated/html/index.en.html

8 For a methodological and numerical comparison between CBD indicators and IMF financial soundness indicators, see Agresti, Baudino, and Poloni (2008) 
As mentioned above, CBD have been, at least partially, available since June 2010 on a twiceyearly basis, with a lag of slightly more than three months after the end of the reporting period (the lag increases to five months for the larger set of annual data). They are consolidated across all countries and financial sectors (excluding insurance companies and non-financial corporations) on a home-country basis. The availability of non-consolidated, host-country data for the banking sector is higher, more frequent and timely and this data may therefore be seen as a potential substitute for consolidated data. In this section, we explore the differences (and the reasons for those differences) between the two datasets, using the Monetary Financial Statistics (MFI) available at the ECB as a reference for non-group-consolidated banking statistics.

The methodological differences in collecting and assembling statistics, summarized in Table 2, mean that a direct comparison of the two sets of data is not straightforward (Annex 1 provides a more detailed description of the difference between CBD and MFI statistics). ${ }^{9}$ However, given that MFI statistics are de facto also used for macro-prudential analysis, due to their completeness in

9 See also the methodological manual drawn up by the Joint Expert Group on Reconciliation of credit institutions' statistical and supervisory reporting requirements (JEGR) at http://www.ecb.europa.eu/pub/pdf/other/mfibalancesheetinterestratesstatisticscebsguidelines201002en. pdf

\section{Table 2 Comparison between MFI balance sheet statistics and CBD}

\begin{tabular}{|c|c|c|}
\hline & MFI balance sheet & CBD \\
\hline Main purpose & Monetary analysis & Banking stability analysis \\
\hline Coverage & $\begin{array}{l}\text { Euro area (also largely reported by } \\
\text { non-euro area EU countries) }\end{array}$ & EU countries \\
\hline Reporting population & $\begin{array}{l}\text { Monetary Financial Institutions (MFI), } \\
\text { including Money Market Funds (MMF). }\end{array}$ & $\begin{array}{l}\text { All domestic credit institutions, as defined in national laws, } \\
\text { as well as branches and subsidiaries of foreign banks. }\end{array}$ \\
\hline Country allocation & Host country (residency) & Home country \\
\hline $\begin{array}{l}\text { Geographical } \\
\text { consolidation }\end{array}$ & $\begin{array}{l}\text { Unconsolidated (solo), excluding foreign } \\
\text { branches and subsidiaries. }\end{array}$ & $\begin{array}{l}\text { Domestic banking groups and foreign subsidiaries are } \\
\text { cross-border consolidated i.e., foreign branches and } \\
\text { subsidiaries are included in the consolidation. }\end{array}$ \\
\hline Sector consolidation & $\begin{array}{l}\text { Only possible for MFIs (not necessarily group } \\
\text { related). }\end{array}$ & $\begin{array}{l}\text { Domestic banking groups and foreign subsidiaries } \\
\text { are cross-sector consolidated (definition of COREP } \\
\text { given in the EU Capital Requirements Directive } \\
\text { 2006/48/EC, excluding all insurers and non-financial } \\
\text { corporations) }\end{array}$ \\
\hline Valuation & $\begin{array}{l}\text { Currency at nominal value. Deposits and } \\
\text { loans at nominal amount and on a gross basis. } \\
\text { Securities at market value (preferred) } \\
\text { or book value as defined in the relevant } \\
\text { national accounting standards (accepted). }\end{array}$ & IASs/IFRSs or national GAAP \\
\hline $\begin{array}{l}\text { Counterparty } \\
\text { breakdown }\end{array}$ & According to ESA 95 sector breakdown & $\begin{array}{l}\text { Less granular (more granular in the source - FINREP } \\
\text { and COREP) }\end{array}$ \\
\hline Maturity breakdown & Original maturity & No maturity breakdown \\
\hline Data content & On-balance sheet items + securitisation & $\begin{array}{l}\text { On- and off-balance sheet items, profit and loss, asset } \\
\text { quality and capital adequacy data }\end{array}$ \\
\hline Mandatory application & Yes, in the case of euro area countries & $\begin{array}{l}\text { CBD is based on a best-effort basis and is addressed to } \\
\text { all EU countries (COREP is mandatory at supervisory } \\
\text { level, FINREP only in some countries and not applied } \\
\text { by non-IFRS banks) }\end{array}$ \\
\hline
\end{tabular}


terms of sector and geographical counterpart analysis, their timeliness, frequency and accuracy, it is interesting to carry out a comparison between the two datasets and understand the main differences between them. In order to gauge the differences and possible similarities between the two datasets, three variables have been selected and analysed in the following sections on account of their availability in both datasets and their relevance: total assets, total loans and total interbank deposits. Box 1 describes how MFI and CBD data could be reconciled. This exercise helps to frame the comparative results presented in the next sections.

\section{Box I}

\section{RECONCILIATION OF MFI AND CBD DATA}

In order to bridge MFI statistics with $\mathrm{CBD}$ at country level, it would be necessary to:

- concentrate on credit institutions (banks);

- include in MFI statistics assets belonging to non-bank institutions within the group (excluding insurers and non-financial corporations);

- include in MFI statistics assets belonging to banks within the group outside the country;

- reallocate cross-border bank branches and subsidiaries, according to the group concept;

- net out intra-group transactions from MFI statistics;

- adjust valuation concepts;

- reconcile reporting population following national (CBD) and EU definitions (MFI) for credit institutions.

\section{I TOTAL ASSETS}

Table 3 displays total assets reported at national level under MFI statistics and CBD frameworks, at end-2011. For MFI statistics, in order to derive banking assets only, the difference between the total assets of other MFIs (i.e. MFIs excluding the ECB and the national central banks of the euro area) and the outstanding stock of money market funds shares/units on the liabilities side of the other MFIs aggregated balance sheets is displayed in the table. ${ }^{10}$

Looking at the data, at EU level the difference between total assets reported in CBD and MFI statistics is rather low (around 1\% of total MFI assets); this means that the effects described in Box 1 tend to compensate each other within the aggregate. However, differences are material for

10 Total assets for credit institutions only are also available quarterly, but for euro area countries only (http://sdw.ecb.europa.eu/browse. do?node=8257837). Internal calculations showed, however, that the difference between total assets of other MFIs and the money market funds shares/units is an excellent proxy of the total assets of credit institutions. 


\begin{tabular}{|c|c|c|c|c|c|c|c|}
\hline \multicolumn{8}{|c|}{ (EUR billion) } \\
\hline \multicolumn{2}{|c|}{ MFI data } & \multicolumn{4}{|c|}{ CBD data } & \multirow{2}{*}{$\begin{array}{r}\text { Difference } \\
(2)-(1)\end{array}$} & \multirow{2}{*}{$\begin{array}{l}\text { Percentage } \\
\text { difference }^{1}\end{array}$} \\
\hline Total (1) & & & Domestic & Foreign & Total (2) & & \\
\hline $\mathrm{BE}$ & 1,196 & $\mathrm{BE}$ & 556 & 591 & 1,147 & -49 & -4 \\
\hline BG & 42 & BG & 9 & 30 & 39 & -3 & -7 \\
\hline $\mathrm{CZ}$ & 180 & $\mathrm{CZ}$ & 9 & 159 & 168 & -12 & -7 \\
\hline DK & 1,145 & DK & 807 & 113 & 920 & -225 & -20 \\
\hline $\mathrm{DE}$ & 8,387 & $\mathrm{DE}$ & 7,577 & 419 & 7,996 & -391 & -5 \\
\hline $\mathrm{EE}$ & 19 & $\mathrm{EE}$ & 1 & 19 & 20 & 1 & 4 \\
\hline IE & 1,028 & IE & 381 & 812 & 1,193 & 165 & 16 \\
\hline GR & 476 & GR & 343 & 82 & 425 & -51 & -11 \\
\hline ES & 3,613 & ES & 3,604 & 311 & 3,915 & 302 & 8 \\
\hline FR & 8,048 & FR & 6,451 & 223 & 6,674 & $-1,373$ & -17 \\
\hline IT & 4,043 & IT & 2,558 & 237 & 2,794 & $-1,248$ & -31 \\
\hline CY & 132 & $\mathrm{CY}$ & 86 & 40 & 125 & -6 & -5 \\
\hline LV & 29 & LV & 10 & 16 & 26 & -3 & -11 \\
\hline LT & 25 & $\mathrm{LT}$ & 2 & 21 & 24 & -1 & -4 \\
\hline LU & 804 & $\mathrm{LU}$ & 63 & 733 & 795 & -9 & -1 \\
\hline $\mathrm{HU}$ & 110 & $\mathrm{HU}$ & 43 & 67 & 110 & -1 & -1 \\
\hline MT & 51 & MT & 10 & 41 & 52 & 1 & 1 \\
\hline NL & 2,425 & NL & 2,514 & 318 & 2,832 & 407 & 17 \\
\hline AT & 1,009 & $\mathrm{AT}$ & 874 & 293 & 1,166 & 158 & 16 \\
\hline PL & 310 & PL & 108 & 190 & 297 & -13 & -4 \\
\hline PT & 573 & PT & 399 & 114 & 513 & -61 & -11 \\
\hline RO & 91 & RO & 14 & 70 & 84 & -7 & -8 \\
\hline SI & 52 & SI & 38 & 15 & 53 & 1 & 1 \\
\hline SK & 58 & SK & 6 & 49 & 55 & -2 & -4 \\
\hline FI & 633 & FI & 140 & 494 & 634 & 1 & 0 \\
\hline SE & 1,129 & SE & 1,611 & 7 & 1,618 & 489 & 43 \\
\hline UK & 9,726 & UK & 7,688 & 3,455 & 11,143 & 1,417 & 15 \\
\hline Total EU & 45,333 & Total EU & 35,902 & 8,916 & 44,818 & -516 & -1 \\
\hline
\end{tabular}

several national banking systems. Typically, CBD total assets are significantly higher in the case of Sweden, Netherlands, the United Kingdom and Austria. At the same time, in countries like Italy, Denmark and France MFI total assets display higher figures. In general, CBD total assets are higher than MFI total assets in countries where domestic banking institutions have important branches/subsidiaries abroad or important domestic non-bank branches/subsidiaries and have an ownership and governance structure that is hinged more on banking/financial groups and less on single institutions. The reverse is true in countries where there is a substantial number of intra-group positions that are netted out at CBD level, due to the presence of large groups and/or small highly interconnected groups. Finally, some difference may be explained by discrepancies between the two reporting populations (for instance, data on small banks are not available for Italy and France).

\subsection{TOTAL LOANS}

Within the CBD reporting scheme, loans granted (and advances) are reported broken down by portfolio and without any counterparty breakdown. This means that a comparison between CBD and MFI loans can be carried out only at the most aggregated level, considering all the reported loans for both data sources. A further caveat must be mentioned: MFI interbank loans comprise a part of the assets of the MMFs that cannot be disentangled from the total without supplementary 


\section{Table 4 Total loans under MFI statistics and CBD, by country, end-20II}

\begin{tabular}{|c|c|c|c|c|c|c|c|}
\hline \multicolumn{8}{|c|}{ (EUR billion) } \\
\hline \multicolumn{2}{|c|}{ MFI data } & \multicolumn{4}{|c|}{ CBD data } & \multirow{2}{*}{$\begin{array}{r}\text { Difference } \\
(2)-(1)\end{array}$} & \multirow{2}{*}{$\begin{array}{l}\text { Percentage } \\
\text { difference }^{1)}\end{array}$} \\
\hline Total (1) & & & Domestic & Foreign & Total (2) & & \\
\hline $\mathrm{BE}$ & 691 & $\mathrm{BE}$ & 350 & 335 & 685 & -6 & -1 \\
\hline $\mathrm{DE}$ & 5,464 & $\mathrm{DE}$ & 4,438 & 291 & 4,729 & -734 & -13 \\
\hline $\mathrm{EE}$ & 18 & $\mathrm{EE}$ & 0 & 15 & 15 & -3 & -16 \\
\hline IE & 696 & IE & 250 & 258 & 508 & -187 & -27 \\
\hline GR & 341 & GR & 250 & 71 & 320 & -20 & -6 \\
\hline ES & 2,371 & ES & 2,442 & 246 & 2,688 & 316 & 13 \\
\hline FR & 5,137 & FR & 3,539 & 88 & 3,627 & $-1,510$ & -29 \\
\hline IT & 2,596 & IT & 1,753 & 179 & 1,932 & -664 & -26 \\
\hline $\mathrm{CY}$ & 99 & $\mathrm{CY}$ & 63 & 30 & 94 & -6 & -6 \\
\hline LU & 600 & LU & 36 & 508 & 543 & -57 & -9 \\
\hline MT & 33 & MT & 6 & 27 & 33 & -1 & -2 \\
\hline NL & 1,704 & NL & 1,753 & 166 & 1,919 & 215 & 13 \\
\hline AT & 735 & $\mathrm{AT}$ & 592 & 222 & 815 & 79 & 11 \\
\hline PT & 361 & PT & 290 & 92 & 382 & 21 & 6 \\
\hline SI & 41 & SI & 28 & 12 & 40 & -1 & -2 \\
\hline SK & 40 & SK & 3 & 35 & 39 & -1 & -3 \\
\hline FI & 374 & FI & 96 & 131 & 226 & -148 & -39 \\
\hline Total EA & 21,301 & Total EA & 15,890 & 2,705 & 18,595 & $-2,706$ & -13 \\
\hline
\end{tabular}

Sources: ECB and ESCB.

Note: 1) Computed as [(CBD total / MFI total)-1]*100.

information. For this reason, the following comparison is confined to euro area countries, for which quarterly "pure" credit institutions data are available. Valuation issues are also to be considered, keeping in mind that MFI loans are recorded at nominal value, while CBD loans are recorded according to the portfolio they are comprised in.

As presented in Table 4, CBD figures are more than 10\% lower than MFI data (in terms of total assets the euro area difference is $2 \%$ ), highlighting the importance of intra-group loans (that are netted out in CBD). This effect is particularly relevant in the case of Finland, Italy, France and Ireland. In a few countries CBD data actually exceed MFI data, meaning that the intra-group loans effect just described is less present or compensated for by important cross-border branches/ subsidiaries.

\subsection{TOTAL INTERBANK DEPOSITS}

The same kind of analysis is performed on interbank deposits. The figures currently displayed for CBD correspond to "amounts owed to credit institutions" and for MFI statistics we present "total interbank loans received" (including loans from non-residents). Again, the same caveat as described for loans applies and therefore the focus is on the euro area only.

Table 5 shows that there are very large differences between MFI and CBD interbank deposits figures both at euro area and at country level. CBD values are around 50\% lower than MFI values for the euro area as a whole, ranging from $-1 \%$ in Malta to $-76 \%$ in Ireland and France. This highlights the role of the group, and in particular of interbank loans, in providing funding in the different countries. Estonia is the only country where values for $\mathrm{CBD}$ are higher than MFI values. 


\section{Table 5 Total interbank deposits under MFI statistics and CBD, by country, end-20I I}

\begin{tabular}{|c|c|c|c|c|c|c|c|}
\hline \multicolumn{8}{|c|}{ (EUR billion) } \\
\hline \multicolumn{2}{|c|}{ MFI data } & \multicolumn{4}{|c|}{ CBD data } & \multirow{2}{*}{$\begin{array}{r}\text { Difference } \\
(2)-(1) \\
\end{array}$} & \multirow{2}{*}{$\begin{array}{l}\text { Percentage } \\
\text { difference }^{1}\end{array}$} \\
\hline Total (1) & & & Domestic & Foreign & Total (2) & & \\
\hline $\mathrm{BE}$ & 290 & $\mathrm{BE}$ & 53 & 77 & 130 & -160 & -55 \\
\hline $\mathrm{DE}$ & 1,833 & $\mathrm{DE}$ & 1,216 & 79 & 1,295 & -537 & -29 \\
\hline $\mathrm{EE}$ & 4 & $\mathrm{EE}$ & 0 & 5 & 5 & 0 & 6 \\
\hline IE & 472 & IE & 18 & 94 & 112 & -360 & -76 \\
\hline GR & 121 & GR & 11 & 34 & 45 & -77 & -63 \\
\hline ES & 687 & ES & 274 & 209 & 483 & -203 & -30 \\
\hline FR & 2,693 & FR & 637 & 22 & 659 & $-2,034$ & -76 \\
\hline IT & 916 & IT & 304 & 82 & 387 & -530 & -58 \\
\hline $\mathrm{CY}$ & 41 & $\mathrm{CY}$ & 6 & 21 & 27 & -14 & -35 \\
\hline LU & 375 & LU & 5 & 350 & 355 & -20 & -5 \\
\hline MT & 21 & MT & 1 & 19 & 20 & 0 & -1 \\
\hline NL & 419 & NL & 137 & 136 & 273 & -146 & -35 \\
\hline AT & 274 & $\mathrm{AT}$ & 152 & 55 & 208 & -66 & -24 \\
\hline PT & 156 & PT & 23 & 52 & 75 & -82 & -52 \\
\hline SI & 15 & SI & 7 & 7 & 14 & -1 & -4 \\
\hline SK & 4 & SK & 0 & 2 & 2 & -2 & -50 \\
\hline FI & 171 & FI & 7 & 125 & 132 & -39 & -23 \\
\hline Total EA & 8,492 & Total EA & 2,851 & 1,370 & 4,221 & $-4,271$ & -50 \\
\hline
\end{tabular}

The analysis conducted in this section shows that important differences exist between consolidated and non-consolidated banking data for the EU and the euro area. Even if these differences are somewhat balanced in terms of total assets in the EU and the euro area, significant differences remain at the country level. Furthermore, the "balancing effect" is reduced as we move towards a more detailed analysis of different balance sheet items. 
The CBD allows to broadly distinguish four main groups of countries within the EU banking system, according to the size of their banking systems and their bank-type ownership structures (predominantly domestic or foreign banks) (see Chart 1):

- In the first group, the size of the banking system is predominantly below $200 \%$ of GDP and is mainly composed of foreign-controlled institutions. This group mainly includes central and eastern European countries: Bulgaria, Czech Republic, Estonia, Hungary, Lithuania, Latvia, Poland, Romania and Slovakia, but also Belgium and Finland (these two countries having somewhat larger banking systems).

- A second group comprises Ireland and Malta, with banking systems weighting between $700 \%$ and $800 \%$ of GDP and mainly composed of foreign-controlled institutions.

- The third group includes countries mainly composed of domestic banking groups: Austria, Cyprus, Denmark, France, Germany, Greece, Italy, the Netherlands, Portugal, Slovenia, Spain, Sweden and the United Kingdom. Their banking system size ranges from 149\% (Slovenia) to $706 \%$ (Cyprus) of GDP.

- Lastly, one can distinguish Luxembourg, where foreign-controlled institutions represent $92 \%$ of total assets and the size of the banking system is $1857 \%$ of GDP.

Chart 2 displays the changes in size and ownership structure of EU banks from 2006, that is, before the financial crisis, to 2011. The main changes concern: Ireland and Finland, for which the size of the banking system in relation to GDP and the relevance of foreign banks increased; Belgium and Luxembourg, where the banking system is now smaller, as compared to GDP, and the weight of

\section{Chart I Size and ownership structure} of EU banks (end-20II)

\section{(percentages)}

$\mathrm{x}$-axis: banks' total assets to GDP

$\mathrm{y}$-axis: foreign controlled banks'assets as a percentage of total assets

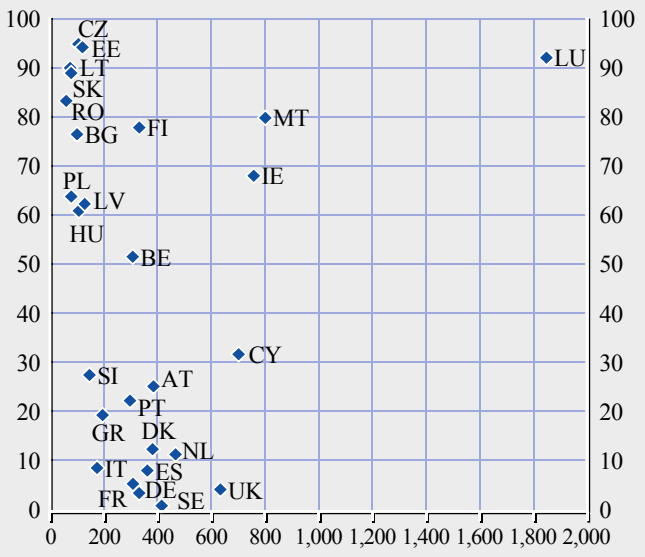

Sources: ECB, ESCB and Eurostat.

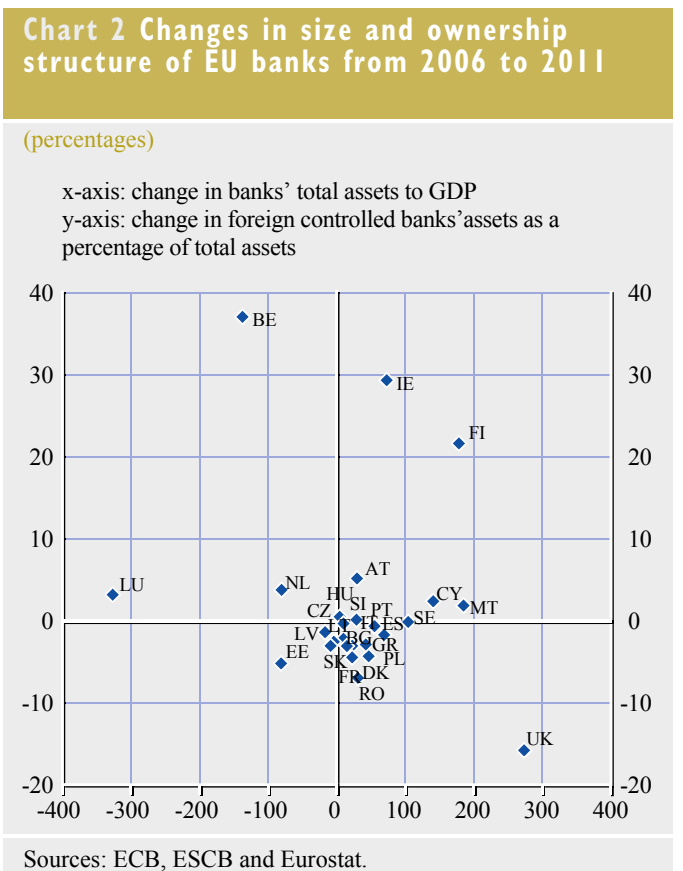




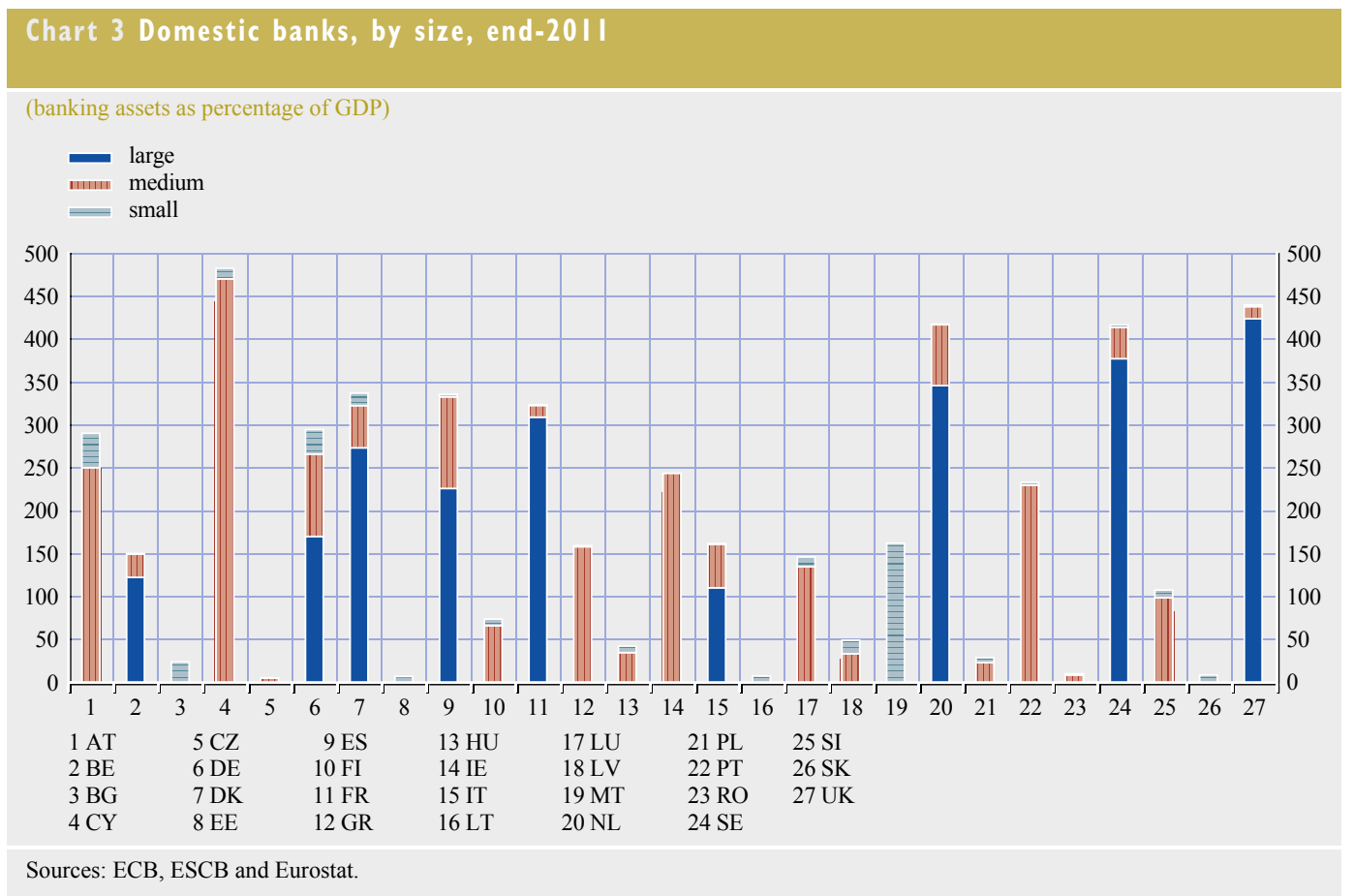

foreign banks increased; and the United Kingdom, with the size of its banking system relative to GDP higher than in 2006 but with domestic banks having become more relevant. In general, for the majority of the countries the size of the banking system in relation to GDP increased between 2006 and 2011 and the relevance of domestic institutions in the national banking systems also increased. These changes are also affected by mergers and acquisition.

As to the breakdown of domestic banks by bank size (see Chart 3), large banks are present in Belgium, Germany, Denmark, Spain, France, Italy, the Netherlands, Sweden and the United Kingdom. ${ }^{11}$ In Bulgaria, Estonia, Lithuania, Malta and Slovakia there are only small banks and the remaining countries have mainly medium-sized banks. It must, however, be borne in mind that the thresholds for the size categories are defined at EU level, so that a "small" bank according to the EU scale may not necessarily be "small" from the point of view of individual countries.

Focusing on large banking groups' data (usually available with a shorter delay) is undoubtedly a powerful tool for monitoring EU financial stability. However, the assessment of large banks should be complemented with the monitoring of small and medium-sized banks. The first reason for this is that, as explained above, large banks are concentrated in nine of the $27 \mathrm{EU}$ countries (and in some of them, medium-sized and small banks also play a significant role). Financial instability affecting small or medium-sized banks, even if concentrated in one country, may have a severe impact on that country and contagion effects through direct (balance sheet connections among institutions) or indirect channels (common exposure to sovereign risk is an example of a potential indirect channel). The second reason is that large, medium-sized and small banks do behave differently and have different business models. Thus, monitoring only the large EU banking groups provides a partial picture. This is illustrated in Chart 4: the Tier 1 ratio, capturing the solvency of the banks, decreases as bank size increases (small banks' Tier 1 ratios are almost double the figures of

11 For reasons of confidentiality, a country with only one or two large institutions may not report data within the "large banks" group. 
(simple average across countries)

_ small banks

.... medium banks

=-= large banks

\section{a) Return on equity}

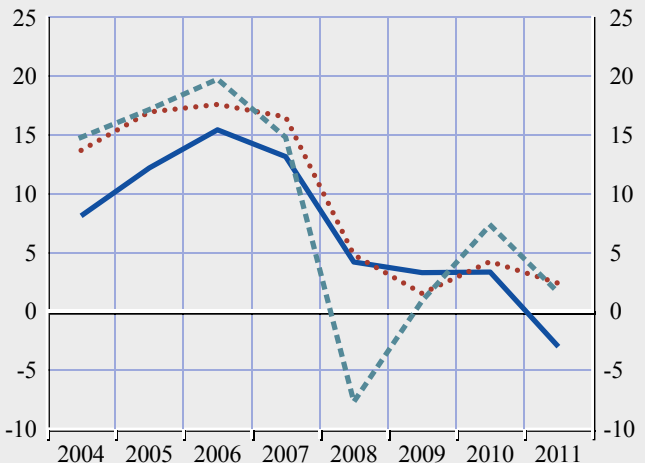

c) Non-performing loans and securities (to total loans and securities)

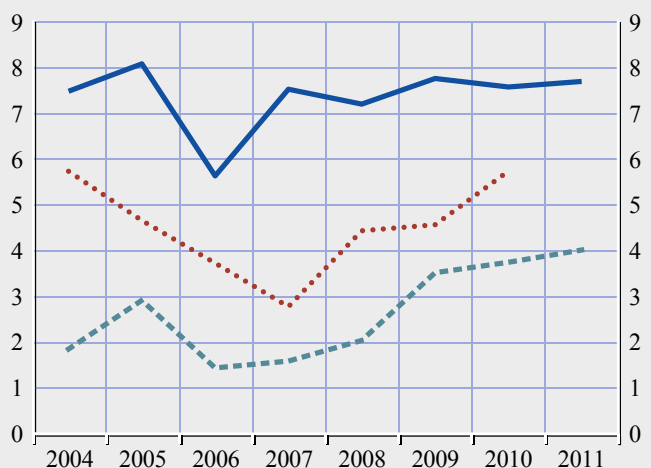

e) Loans-to-deposits ratio

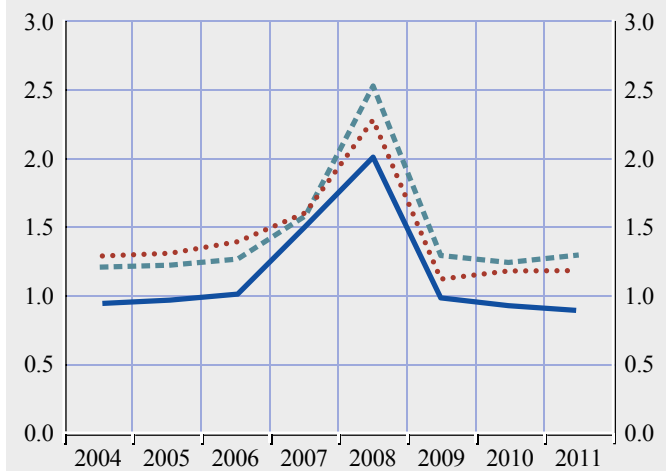

b) Tier 1 ratio

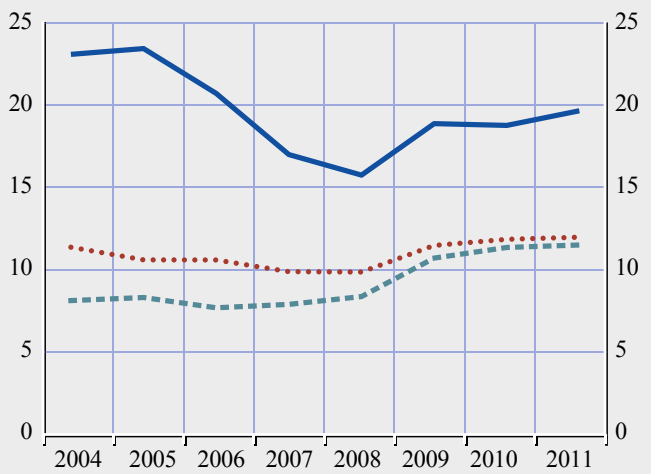

d) Assets to equity (leverage)

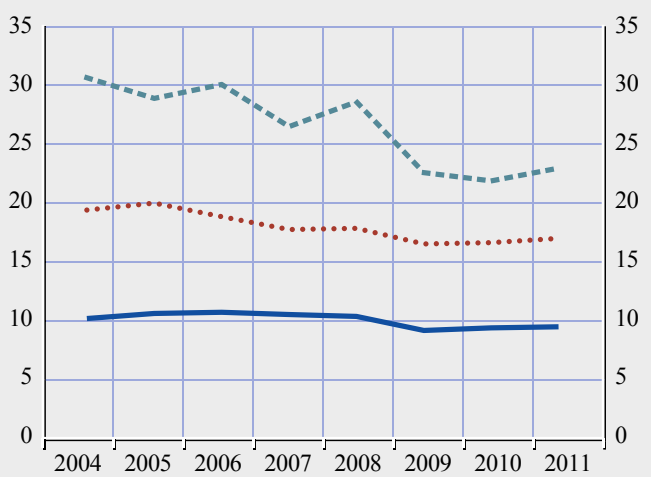

Sources : ECB and ESCB

Notes: The following outliers were removed from the analysis: ROE Portugal (small banks) 2008 and 2009; ROE Ireland (medium-sized banks) 2010; ROE Cyprus (medium-sized banks) 2010; ROE Greece (mediumsized banks) 2011; AtE Netherlands (small banks) 2008; AtE Portugal (small banks) 2009; AtE Greece (medium-sized banks) 2011 


\section{Chart 5 Foreign banks, by region of control}

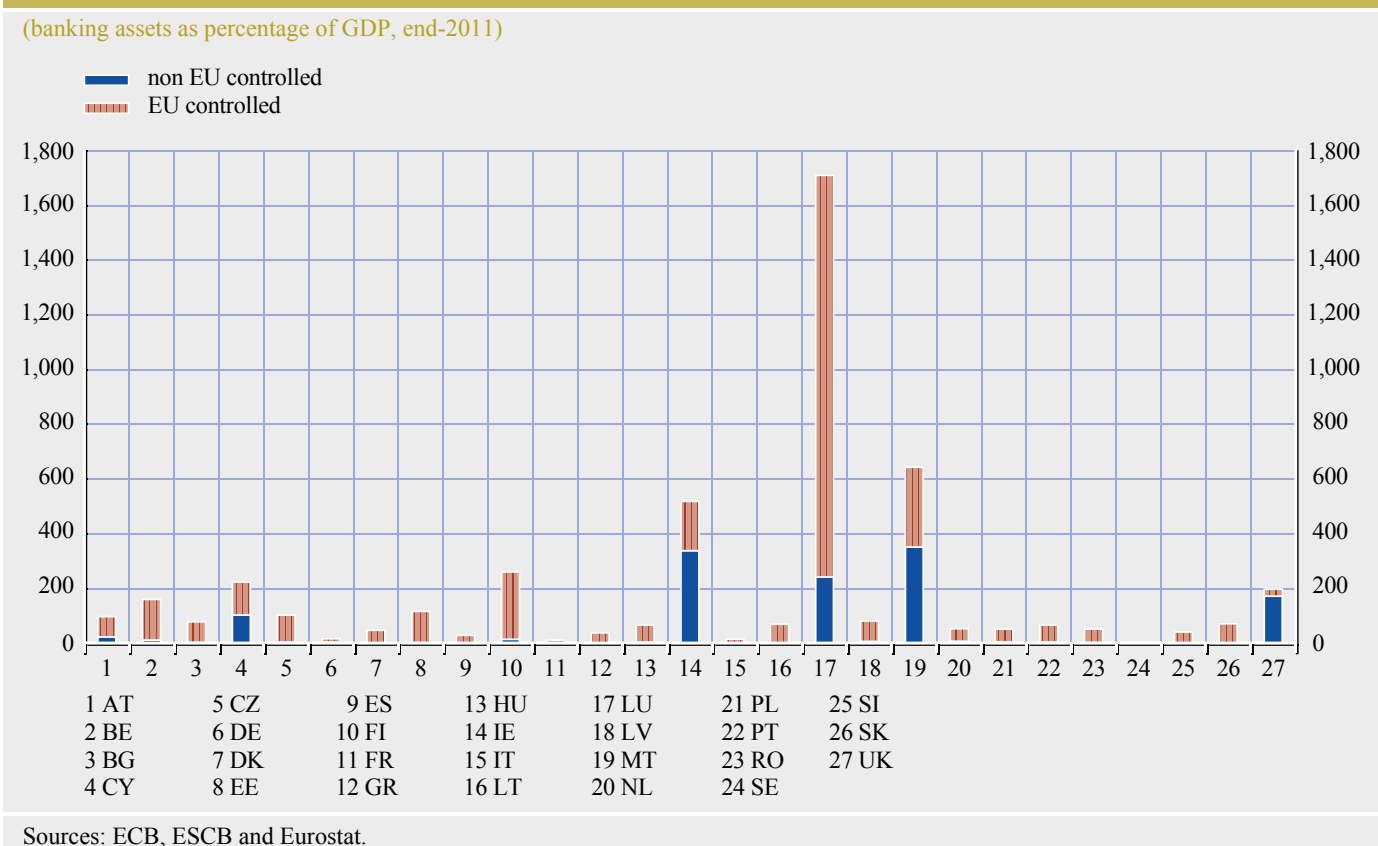

large banks); non-performing loans and securities, a measure of asset quality, also decreases as bank size goes up, with smaller banks presenting significantly higher ratios; leverage increases with bank size and the deleveraging process can mainly be observed for larger banks; the loansto-deposit ratio also increases with bank size. As for return on equity, it seems that large banks are more affected by downturns, as their return on equity was significantly impacted by the financial crisis in 2008.

Lastly, concerning foreign-controlled banks active in a particular EU country, Chart 5 shows that these banks are largely controlled by a parent bank resident in another EU country, whereas non-EU foreign controlled banks represent a small share of the national GDP. Non-EU foreign controlled banks are significant in Cyprus, Ireland, Luxembourg, Malta and the United Kingdom. 


\section{Table 6 Benchmark periods}

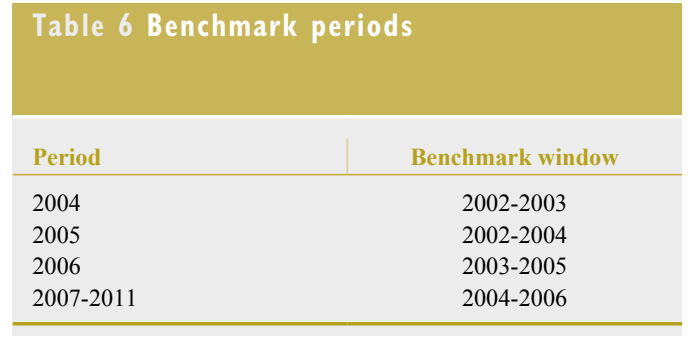

CBD data may be used to identify periods of stress in the EU financial system, their extent and their severity. By analysing the behaviour of some relevant financial stress indicators as compared to their benchmark behaviour, it is possible to identify periods and countries where deviations are significant. The choice of the indicators, on the one hand, and of the benchmark, on the other hand, is therefore crucial for the results. For the purposes of this paper we have selected indicators that are seen as key for financial stability assessment (see Table 1).

Concerning benchmark behaviour, it would be interesting to consider two dimensions: what is considered "normal" across countries as well as across time. To capture both dimensions, as a benchmark for a given period and country we have taken the mean across countries over the latest three years for which data were available. During a crisis, the benchmark window must be frozen in the pre-crisis period in order to correctly capture the deviations from "normal" times (meaning that, in the calculation of benchmarks, we have excluded the years from 2007 onwards). Given the time span of our sample (2002-2011), the benchmark periods considered are described in Table 6. ${ }^{12}$

The approach presented in this paper is based on the compilation, for each country and bank size, of the standardised value $z_{t, i}$ of each indicator $x_{t, i}$, using the mean $\bar{x}_{t-3 ; t-1}$ and standard deviation $\sigma_{t-3 ; t-1}$ across all countries of the last three periods of available data:

$$
z_{t, i}=\frac{x_{t, i}-\bar{x}_{t-3 ; t-1}}{\sigma_{t-3 ; t-1}}
$$

where $t$ is the time dimension and $i$ is the relevant country. In order to provide summary measures for the EU and based on the z-score approach presented above, this paper proposes the following. As a first step, compiling, for each period and indicator, the mean and standard deviation of the standardised variables across countries, as presented in equations (2) and (3):

$$
\begin{gathered}
\bar{z}_{t}^{\prime}=\frac{1}{N} \sum_{i} z_{t, i}^{\prime} \\
\sigma_{t}^{z}=\frac{1}{N} \sum_{i}\left(z_{t, i}-\bar{z}_{t}\right)
\end{gathered}
$$

where $N$ is the number of countries. In addition, since the sign of each standardised variable may have different implications (there may be "good" and "bad" deviations from the benchmark for instance, an above average Tier 1 ratio is not a "bad" deviation), we perform some transformations to $z$, represented by $z$ ', before the computation of equation 2 (see Table 7). It is assumed that negative deviations from the benchmark are bad in the case of the Tier 1 ratio, but good in the case of non-performing loans and

12 As the number of years in the sample increases, it will be possible to consider longer benchmark windows (e.g. five years). For 2004 only two years are considered, given that the time series start in 2002 .

Table 7 Transformed standardised variables for the computation of the mean across countries

\begin{tabular}{l|l} 
Variables & Transformed $z_{t}$
\end{tabular}

- Return on equity $\quad z_{t, i}^{\prime}=2-z_{t, i}$ if $z_{t, i}>1$

- Tier $1 \quad$ No transformation needed

- Non-performing and doubtful loans

and debt securities (percentage of

total loans and debt securities) $\quad z_{t, i}^{\prime}=-z_{t, i}$

- Loans-to-deposits ratio

- Assets to equity 
securities, the loans-to-deposits ratio and assets to equity (leverage). In the case of return on equity, this paper considers that negative deviations are bad (in the sense that lower than normal returns are bad) but, at the same time, a too high positive deviation can signal excessive risk taking.

In this way, the average for each period has a clear interpretation: the more negative the average, the higher the potential stress in the banking sector. Concerning the standard deviation (equation 3), values above 1 are seen as periods of increased volatility and, therefore, may signal periods of financial instability.

\section{Chart 6 Average and standard deviation of the z-scores across countries, by bank type}

\begin{tabular}{|c|c|c|c|c|}
\hline & 2004 & $X X X X A$ & 2007 & $20 \times 0 \times 0 \times$ \\
\hline ตини & 2005 & atw & 2008 & 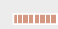 \\
\hline & 2006 & 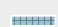 & 2009 & \\
\hline
\end{tabular}

a) Small banks - average

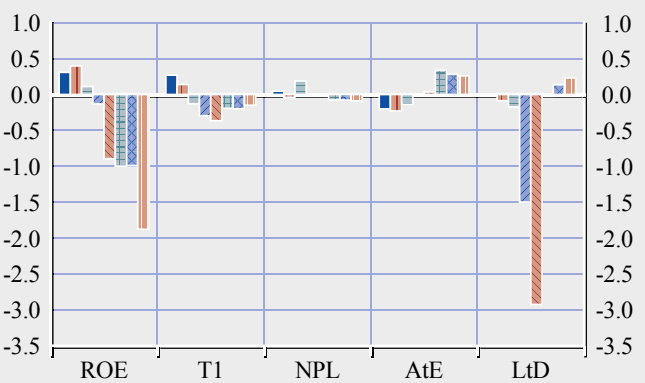

c) Medium-sized banks - average

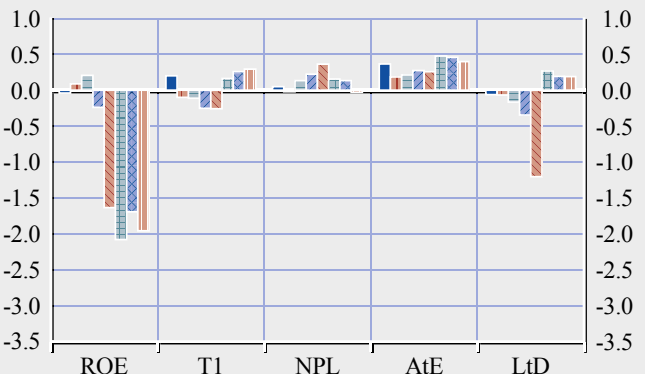

e) Large banks - average

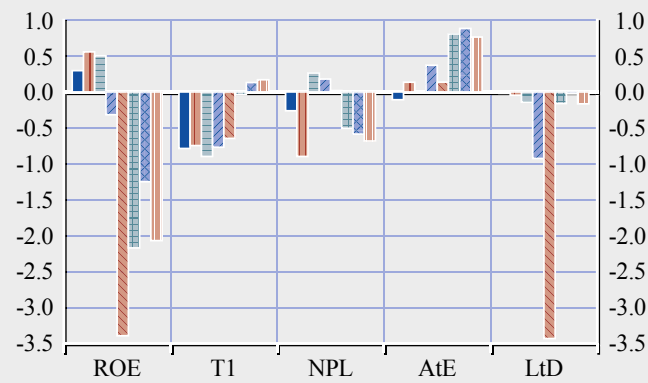

b) Small banks - standard deviation

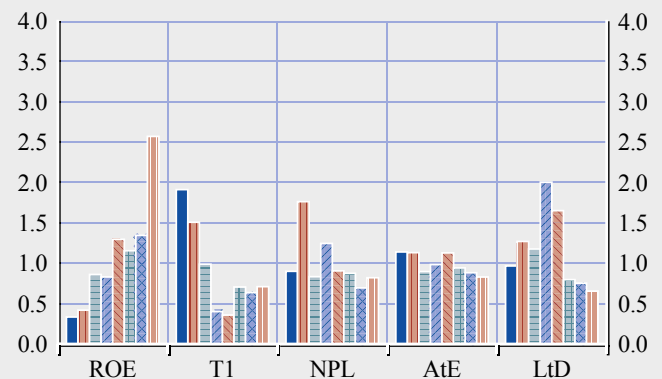

d) Medium-sized banks - standard deviation

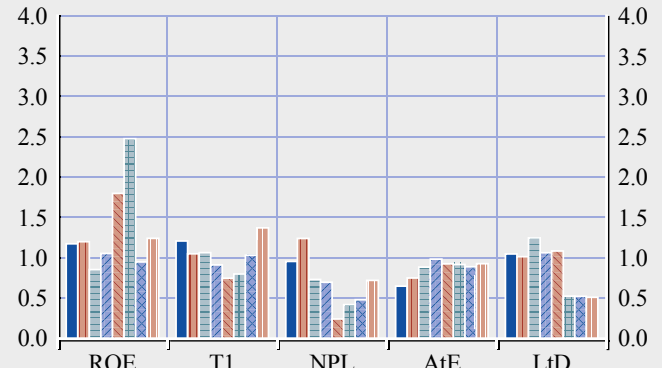

f) Large banks - standard deviation

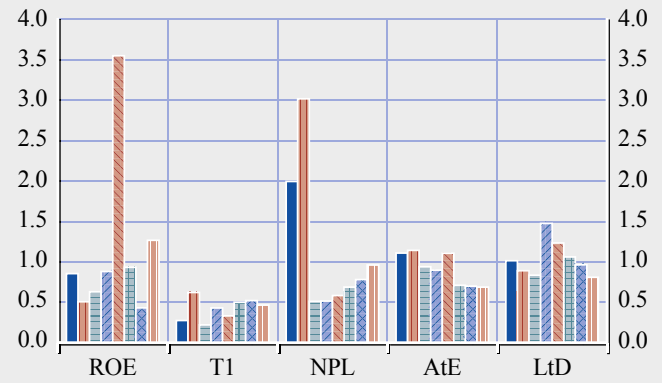

Sources: ECB, ESCB and authors' calculations.

Notes: The following outliers were removed from the analysis: ROE Portugal (small banks) 2008 and 2009; ROE Ireland (mediumsized banks) 2010; ROE Cyprus (medium-sized banks) 2010; Greece (medium-sized banks) 2011; AtE Netherlands (small banks) 2008; AtE Portugal (small banks) 2009; AtE Greece (medium-sized banks) 2011. 
The results of this approach are presented in Chart 6.

The second step is to summarise the information presented above for the different indicators, in a single measure. This paper presents simple averages of both the mean and the standard deviation of the five indicators studied (see Chart 7). However, it is possible to assign different weights to the different indicators, to further refine the overall measure. ${ }^{13}$

The analysis in this paper shows that financial stress indicators for large, medium-sized and small banks do behave differently. From Chart 7 (7(a)) one can see that large banks were already below the benchmark in the pre-crisis period and that they were more severely hit by the crisis (although they also recovered quickly to values close to those of smaller banks). In 2011, all bank sizes were still negatively deviating from the benchmark values. Drilling down to the level of indicators (Chart 6, 6(a), 6(c), 6(e)), ROE and loans-to-deposits have the worst performance vis-à-vis the benchmarks. In the case of large banks, the Tier 1 ratio and the non-performing loans and securities variables also show negative deviations from the benchmarks.

In terms of volatility (Chart 7, 7(b)), small and medium-sized banks display values fairly similar to those of the benchmark windows. Concerning large banks, volatility was lower than in the benchmark window in 2006, before the onset of the crisis, and quickly rose to above normal volatility levels in 2008. Since then, large banks have displayed lower volatility than in the benchmark periods.

13 The same is true for countries - this paper implicitly assigns the same weight to the different countries; asymmetric weights may also be envisaged.

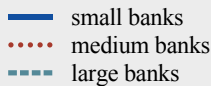

a) Composite average, by bank size

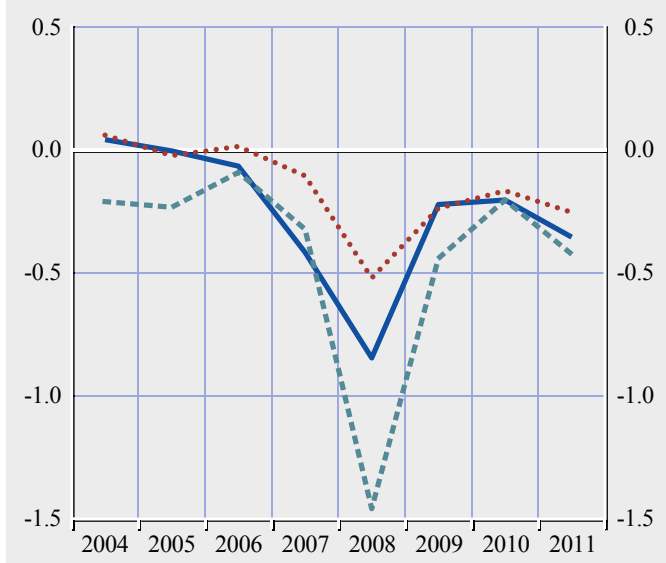

b) Composite standard deviation, by bank size

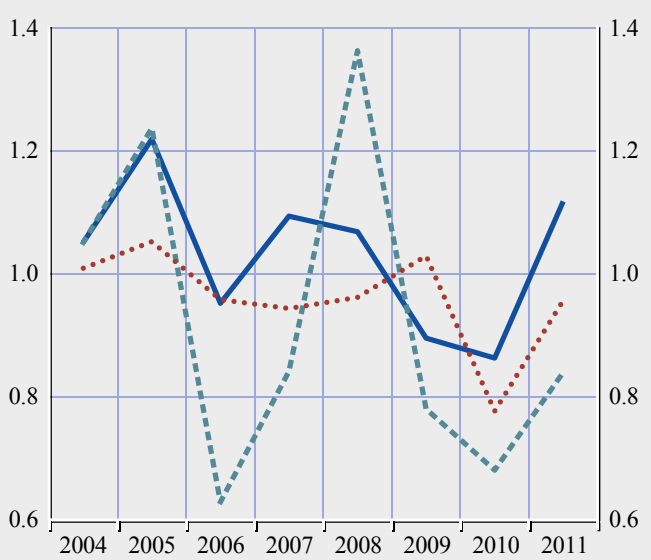

Sources: ECB, ESCB and authors' calculations.

Notes: The following outliers were removed from the analysis: ROE Portugal (small banks) 2008 and 2009; ROE Ireland (medium-sized banks) 2010; ROE Cyprus (medium-sized banks) 2010; Greece (medium-sized banks) 2011; AtE Netherlands (small banks) 2008; AtE Portugal (small banks) 2009; AtE Greece (medium-sized banks) 2011. 
This paper focuses on financial stress indicators for the overall EU banking system. ${ }^{14}$ However, it is possible to drill down and identify the countries and indicators where deviations are more relevant and in doing so assess the need for, and the type of, corrective policy action. In addition, based on the framework presented in this paper, it is possible to develop additional aggregate indicators that are not explored here, such as the number of deviating variables across countries, for each period and given a certain threshold, to assess the severity of the financial distress. This can be complemented by the number of countries with more than, for instance, two deviating indicators, to understand the extent of the crisis. The higher the value of these indicators, the higher the financial stress of the EU banking system and the wider the extent of the financial instability.

As shown in this section, several types of analysis may be conducted with the tools described, possibly helping to shed some light on the level and sources of potential financial instability, and hence enabling policy-makers to act. In fact, aggregated data may be extremely valuable in guiding the analysis of more granular data by signalling where and what to look for. Also, stress indicators for large and non-large banks behave differently and therefore the results of the assessment of large banks cannot be used as a substitute for data on smaller banks. The regular analysis of large EU banks should be complemented with a separate assessment of small and medium-sized banks in the EU.

14 It is important to note that the way the aggregate indicators are compiled implies that we assign the same weight to the different variables The analysis could be fine-tuned in this respect, but further research on the impact (in terms of size and persistence) of the different imbalances would be necessary. 
This paper explores the differences between consolidated banking data and solo/host-country MFI balance sheet statistics, and shows why the latter cannot always satisfactorily substitute the former when analysing financial stability. The value added of aggregated data for financial stability analysis is also put forward, presenting some tools for extracting from aggregated data valuable insights into a focused analysis of micro data. The paper also shows the importance of monitoring smaller banks.

Consolidated banking data are a useful dataset for financial stability analysis. However, their added value may be increased along four lines. The first one is timeliness. A shorter time lag between the observed developments and their analysis would enable a faster and, therefore, more effective response by policy-makers. Frequency is also important. Higher frequency facilitates closer monitoring. Both issues - timeliness and frequency - were significantly improved with the move from annual data, collected five months after the year-end, to twice-yearly data, reported three months after the semester-end. Despite the relevance of any improvement in these areas, the trade-off between frequency/timeliness and accuracy must be kept in mind. Third, the availability of exposures breakdown by country/sector would allow for analyses that are currently not possible. Lastly, the fourth line of improvement concerns the harmonization of the underlying definitions of the CBD items. The work undertaken by the European Banking Authority to finalise the harmonisation of the reporting templates (COREP and FINREP) is a significant step in the right direction. 


\section{METHODOLOGICAL COMPARISON OF CBD AND MFI STATISTICS}

The main statistical input to the monetary pillar of the ECB monetary policy strategy is the aggregated balance sheet of the euro area MFI sector. A detailed monthly balance sheet of the MFI sector in the euro area is the ECB's main source of comprehensive information on monetary and credit developments in the euro area. The ECB requires statistical information with instrument, maturity, currency and counterparty breakdowns (see ECB Regulation /2008/32). The statistical system for the euro area MFI sector comprises two main elements: a list of MFIs as defined for statistical purposes, and a specification of the statistical information reported by these MFIs at monthly and quarterly frequency. The regulation sets out the reporting obligations of euro area MFIs.

The MFI sector comprises, in addition to central banks, two broad groups of resident financial intermediaries: (i) credit institutions, which are defined in EU law (under the Banking Coordination Directives) as "an undertaking whose business is to receive deposits or other repayable funds from the public (including the proceeds arising from the sale of bank bonds to the public) and to grant credits for its own account; or an electronic money institution"; and (ii) other resident financial institutions which meet the criteria for classification as MFIs by issuing financial instruments which are close substitutes for deposits. Money market funds (MMF) make up the predominant share of this second subset of institutions.

There are several methodological differences between CBD and MFI statistics that are the result of their different focus - financial stability and monetary analysis respectively:

- MFI statistics are based on internationally agreed statistical standards (i.e. the System of National Accounts), which are made mandatory in Europe through the European System of Accounts Regulation (1995ESA). CBD are based mainly on national supervisory sources, which are not yet fully harmonised.

- MFI statistics comprise non-consolidated balance sheets, collected on the basis of the "hostcountry approach". This means that data for subsidiaries are not consolidated at group level and branches and subsidiaries controlled by foreign institutions are reported within the aggregate referring to the host country, and not the home country. For example, a German subsidiary of a French bank will be comprised in the German list of MFIs and aggregated in the German contribution to the euro area aggregates. Accordingly, neither sector nor geographical consolidation is carried out for monetary statistics. This approach is essential due to the fact that monetary analysis focuses on the money-holding sector. In contrast, the statistical treatment of CBD is based on group data, on a home-country basis, with geographic and sector (excluding, in most cases, insurance corporations, and also non-financial corporations) consolidation.

- CBD data are reported by the $27 \mathrm{EU}$ countries in accordance with the same reporting scheme (even though there is no legal instrument forming the basis of this data collection). The reporting of MFI statistics is mandatory only for euro area countries under Regulation ECB/2008/32 (however, almost all of these statistics are also reported by non-euro area EU countries).

- The CBD reporting population comprises only banks, i.e. all domestic credit institutions as defined in national law (as well as branches of foreign banks), while the reporting population for monetary statistics also includes MMFs and central banks, as described above. 
- CBD series include both on- and off-balance sheet items, profit and loss, asset quality and capital adequacy data. MFI statistics comprise mainly on-balance sheet items and only some off-balance sheet items (e.g. related to securitisation).

- Concerning valuation criteria, CBD, being derived from FINREP and COREP templates, follow the valuation rules applied in these schemes, namely IAS/IFRS. Few reporting countries still follow local GAAP for (part of their) their reporting system. Valuation criteria for MFI statistics are laid down in the relevant ECB regulation and market (fair) value is also the rule, except for loans and deposits, where nominal value should be reported.

- MFI statistics are generally reported at original maturity brackets, whereas no maturity breakdown is reported under CBD; residual maturity is available for a restricted set of balance sheet items.

- MFI statistics have a rather elaborated (geographical, sector, currency) counterparty breakdown, while CBD items have no counterpart breakdowns.

- MFI statistics allow the calculation of, besides balance sheet amounts, proper statistical transactions, which are necessary to analyse changes over time and growth rates, and, in general, to distinguish valuation and reclassification changes from volume changes. 


\section{REFERENCES}

Agresti, A.M., Baudino, P., and Poloni, P. (2008), "The ECB and IMF indicators for the macro-prudential analysis of the banking sector: a comparison of the two approaches", Occasional Paper Series, No. 99, ECB, Frankfurt am Main, November.

Bakk-Simon, K., Borgioli, S., Giron, C., Hempell, H.S., Maddaloni, A., Recine, F. and Rosati, S. (2012), "Shadow banking in the euro area: an overview", Occasional Paper Series, No. 133, ECB, Frankfurt am Main, April.

Borio, C. (2010), "Implementing a macro-prudential framework: balancing boldness and realism", keynote speech given at the HKIMR-BIS conference on "Financial Stability: Towards a Macroprudential Approach", 5-6 July.

Cecchetti, S.G., Fender, I. and McGuire, P. (2010), “Towards a global risk map", BIS Working Paper, No. 309, May.

Clement, P. (2010), “The term 'macroprudential': origins and evolution”, BIS Quarterly Review, March.

Constâncio, V. (2010), "Macro-prudential regulation as an approach to containing systemic risk: economic foundations, diagnostic tools and policy instruments", ECB speech, Frankfurt am Main, 27 September.

European Central Bank (2007), EU Banking Sector Stability, Frankfurt am Main, November.

European Central Bank (2011), Central bank statistics: what did the financial crisis change?, Fifth ECB Conference on Statistics on 19 and 20 October 2010", http://www.ecb.europa.eu/ pub/pdf/other/centralbankstatistics201102en.pdf, February.

European Central Bank and CEBS (2010), MFI Balance Sheet and Interest Rate Statistics and CEBS' Guidelines on FINREP and COREP, http://www.ecb.europa.eu/pub/pdf/other/ mfibalancesheetinterestratesstatisticscebsguidelines201002en.pdf, February.

IMF (2006), Financial Soundness Indicators - Compilation guide, Washington DC, March, as amended in July 2008. 


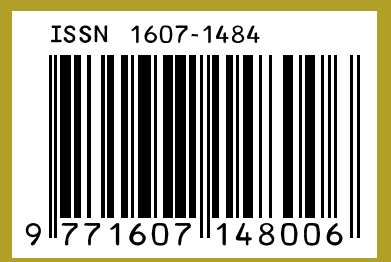

